Article

\title{
Stochastic Analysis of Embodied Carbon Dioxide Emissions Considering Variability of Construction Sites
}

\author{
Dongyoun Lee ${ }^{1} \mathbb{D}$, Goune Kang ${ }^{2} \mathbb{D}$, Chulu $\mathrm{Nam}^{3}{ }^{3}$, Hunhee Cho ${ }^{1, *}$ and Kyung-In Kang ${ }^{1}$ \\ 1 School of Civil, Environmental and Architectural Engineering, Korea University, 145, Anam-ro, \\ Seongbuk-gu, Seoul 02841, Korea \\ 2 Korea Institute of Civil Engineering and Building Technology, 283 Goyang-daero, Ilsanseo-gu, Goyang, \\ Gyeonggi 10223, Korea \\ 3 Deajeon-Sejong-Chungnam Headquarters, Korea Electric Power Corporation, 170, Songchonnam-ro \\ 11beon-gil, Dong-gu, Daejeon 34537, Korea \\ * Correspondence: hhcho@korea.ac.kr; Tel.: +82-2-921-5920; Fax: +82-2-923-4229
}

Received: 30 June 2019; Accepted: 1 August 2019; Published: 4 August 2019

\begin{abstract}
The current method of estimating $\mathrm{CO}_{2}$ emissions during the construction phase does not consider the variability that can occur in actual work. Therefore, this study aims at probabilistic $\mathrm{CO}_{2}$ estimation dealing with the statistical characteristics in activity data of building construction work, focused on concrete pouring work and based on field data. The probabilistically estimated $\mathrm{CO}_{2}$ emissions have some differences from $\mathrm{CO}_{2}$ emissions measured by current deterministic methods. The results revealed that the minimum difference was $11.4 \%$, and the maximum difference was $132.7 \%$. This study also used Monte Carlo simulations to derive information on a probability model of $\mathrm{CO}_{2}$ emissions. Results of the analysis revealed that there is a risk of underestimating emissions because the amount of emissions was estimated at a level that exceeds the $95 \%$ confidence interval of the simulation results. In addition, the probability that $\mathrm{CO}_{2}$ emissions using the measured activities data were less than the estimated $\mathrm{CO}_{2}$ emissions using the bill of quantity was $73.2 \%$ in the probability distribution model.
\end{abstract}

Keywords: $\mathrm{CO}_{2}$ emissions; construction phase; stochastic analysis; Monte Carlo simulation

\section{Introduction}

The building sector consumes about $40 \%$ of the world's annual energy production, which accounts for approximately a quarter of the world's annual $\mathrm{CO}_{2}$ emissions [1]. Continuous efforts have been made to reduce the amount of $\mathrm{CO}_{2}$ emitted from buildings. Various technological developments and political measures related to eco-friendly building materials or renewable energy usage have been undertaken in the public and private sectors. However, these have tended to focus on specific phases in the whole life of the building, namely, material manufacturing and operational building phases [2,3]. Previous studies also have mentioned that it is important to deal with the embodied carbon emissions generated in the production, construction, maintenance, and disposal of building materials [4]. Among these phases, the construction phase accounts for approximately $10-30 \%$ of the entire building life cycle, even if it represents a short period. The aforementioned highlights the necessity for accurate and detailed estimation of $\mathrm{CO}_{2}$ in order to devise means of reducing emissions from the construction phase [5].

However, estimating or predicting the amount of $\mathrm{CO}_{2}$ generated during the construction phase is difficult because there is variability at the construction site. There is much variability in the input of resource types or quantities because construction activities are performed in outdoor environments [6]. 
Several researchers have utilized bills of quantity or standard productivity information prepared in the design stage, so values were almost fixed by design documents and cannot reflect the actual condition of the construction site.

Therefore, this study aims at probabilistic $\mathrm{CO}_{2}$ estimation dealing with the statistical characteristic in activity data of building construction work, based on field data and considering variability. According to 2006 Intergovernmental Panel on Climate Change (IPCC) guidelines, variability is an inherent property of the system of nature and not of the analyst [7]. In this study, variability is defined as an inherent characteristic of the construction phase work. In addition, the result of the intrinsic characteristics is judged to be the working time. This study used actual activity data gathered during the construction phase and performed Monte Carlo simulation to determine the probabilistic interval of $\mathrm{CO}_{2}$ emissions, focusing on concrete pouring work. Activity data were collected by measuring the operating time of concrete pump cars and concrete mixer trucks, which consume fossil fuels and directly emit $\mathrm{CO}_{2}$. In this study, correlation analysis is performed to derive the correlation coefficients for the emission amount of each activity and to reflect them in the simulation. We executed the simulation test 10,000 times at a $95 \%$ confidence interval.

\section{Literature Review}

A deterministic $\mathrm{CO}_{2}$ emission estimation obtained by multiplying the $\mathrm{CO}_{2}$ emission coefficient with the amount of input material may not be accurate because these inputs do not take into account uncertainties at the construction site. Therefore, a previous study evaluated variability when estimating $\mathrm{CO}_{2}$ emissions and has presented a prediction method that considers this level of variability [8-12].

This study also considered the most-consumed building materials to perform an analysis of statistical properties. Based on this, it probabilistically predicted the materials' construction stage emissions [8,9]. Other studies analyzed the variability of emission coefficients by evaluating the most-consumed building materials based on accumulated greenhouse gas emissions, as well as the energy emissions coefficient, in order to assess the level of uncertainty and variability when estimating the emissions of the apartment housing construction stage $[10,11]$. Another study suggested a method of calculating $\mathrm{CO}_{2}$ emissions by calculating the amount of use of construction equipment on construction sites based on the schedule information of the building construction [12].

The only datum that can be used to quantify the environmental impact of equipment in the construction process is the daily report on the type and quantity of equipment that is deployed at the worksite. However, this data source lacks detailed information on equipment usage. To calculate $\mathrm{CO}_{2}$ emissions using traditional life cycle impact assessment metrics and methods, historical performance data must be compiled with an accurate construction inventory (i.e., materials and equipment used for construction and maintenance work) $[13,14]$. Previous studies estimating $\mathrm{CO}_{2}$ emissions have used simulation methods. The $\mathrm{CO}_{2}$ of equipment used in road construction was calculated by measuring the engine load of the equipment. Moreover, the measured data were applied to the simulation considering the variability of the engine load [15-17]. Regarding equipment, simulation studies also exist. Similarly, other studies used CYCLONE simulation to predict emissions probabilistically while considering the variability of fuel consumption according to the activity of earthwork equipment $[18,19]$.

However, the previous studies mentioned above have limitations, since they focus only on materials, or there is a lack of consideration of activity data, such as the operation time of construction equipment at the activity level. Previous studies have estimated only the amount of $\mathrm{CO}_{2}$ emissions from construction equipment based on the amount of oil the equipment consumes. In addition, the variability in embodied carbon emissions of various building types has been explored [20,21]. However, there is still a lack of statistical information for the activity data for construction. In particular, the distribution type, parameters, and correlations required as input variables for Monte Carlo simulation have not been investigated yet [22]. 
Therefore, in this study, we gathered actual data about the operating time of construction equipment used at the activity level. Moreover, this study presents an estimation method using probabilistic $\mathrm{CO}_{2}$ emissions for analyzing the variability during the construction phase.

\section{Analyzing Variability in $\mathrm{CO}_{2}$ Emissions}

\subsection{Overview of Activity Data Collection}

In order to estimate $\mathrm{CO}_{2}$ emissions, it is necessary to estimate the amount of oil consumption by measuring construction equipment operation time and equipment specification information. Therefore, data were collected on equipment operation time at the activity level (Table 1).

Table 1. Overview of the construction site with activity data collected.

\begin{tabular}{cc}
\hline & Content \\
\hline Project & K Research Building (new construction) \\
Location & Seongbuk-gu, Seoul, Korea \\
Land area & $130,606 \mathrm{~m}^{2}$ \\
Building area & $33,521 \mathrm{~m}^{2}$ \\
Gross floor area & $22,910 \mathrm{~m}^{2}$ \\
Structure type & Reinforced concrete \\
Floors & Six floors and two floors underground \\
Building use & Office building (education and research facility) \\
\hline
\end{tabular}

This study collected data about concrete work for a typical floor slab. In this study, it was difficult to collect activity data for all tasks. Therefore, this study collected data focused on heavy equipment, which uses heavy oil in concrete pouring work; we installed a camcorder and a stopwatch to measure the operating time of each piece of construction equipment, namely, concrete pump cars and concrete mixer trucks.

Based on the specifications of the construction equipment, this study surveyed the equipment that meets the applicable standards of construction machinery expenditure as illustrated by Korean professional construction association information.

\subsection{Calculating Emissions from Equipment Operation Times}

In this study, one work cycle of concrete pouring work was defined from when a concrete mixer truck enters to when the truck leaves the construction site. A total of 37 work cycles were measured. However, interrupted working hours during the work cycle were excluded from the measurement.

The equipment operation time for each detailed task was measured, and 21 data sets were acquired in five categories and used in the analysis. The work of a concrete mixer truck was classified into four detailed tasks: Stopping after entering, waiting after stopping, pouring concrete, and leaving. The detailed work of the concrete pump cars was classified as a single task: Pumping concrete.

To estimate the working time of a concrete pump car for one concrete mixer truck $\left(6 \mathrm{~m}^{3}\right)$, we referred to the average productivity value of the amount pumped per hour $\left(87.5 \mathrm{~m}^{3} / \mathrm{h}\right)$ provided in the Construction Equipment Cost Estimates Table (CECET). The CECET is an annual national standard released by the Construction Association of Korea (CAK) and the Ministry of Land, Infrastructure and Transport (MOLIT) and is calculated and published using data on the hourly hire of machines, miscellaneous materials, and drivers of construction machines listed in the standard production unit system. In this study, the concrete mixer trucks and concrete pump cars used at the construction site were collected through the CECET.

In this study, the $\mathrm{CO}_{2}$ emission coefficients of materials and equipment were used according to the data presented in the 2006 IPCC guidelines [23]. The IPCC provides $\mathrm{CO}_{2}$ emission coefficients through its own data surveys and reports submitted by each country. Recently, each country has used IPCC guidelines to calculate $\mathrm{CO}_{2}$ emission coefficients that fit the situation for that country [17]. 
This study does not consider the working time of concrete mixer trucks at the work planning phase because the number of concrete mixer trucks is calculated at the time of work planning. The working time of the concrete pump car was estimated using the formula (Equation (1)) proposed in the standard for reinforced concrete construction estimation [24]:

$$
T_{p}=t_{p} \times f_{1} \times f_{2} \times Q
$$

where:

$T_{p}$ : Concrete pump car working time;

$t_{p}$ : Reference time, estimated time it takes for the concrete pump car to pour $1 \mathrm{~m}^{2}$;

$f_{1}$ : Facility type consideration coefficient;

$f_{2}$ : Concrete mixer truck entry condition coefficient; and

$Q$ : Workload.

In this study, a reference time $\left(t_{p}\right)$ value was applied- -1.25 min corresponding to $15 \mathrm{~cm}$ of the reinforced concrete slump-by referring to the information provided on the site where the activity data were collected [24]. The working time was calculated under the conditions that $f_{1}$ is normal (1.2) and $f_{2}$ is good (1.0) [24].

The average and the standard deviation of the measured equipment operation time are shown in Table 2. The planned equipment operation time is expressed as a single value. The variation of work time was the largest for waiting after stopping and was relatively low for stopping after entering and leaving. The average measured operation time of concrete pumping work was calculated to about $50 \mathrm{~s}$ longer than the value given by the machine cost calculation table. In addition, the concrete pumping work was more than twice the average measurement time in the case of the bills of quantity.

Table 2. Measured operation time and planned operation time (in seconds).

\begin{tabular}{ccccccc}
\hline Activity & $\begin{array}{c}\text { Stopping } \\
\text { after } \\
\text { Entering }\end{array}$ & $\begin{array}{c}\text { Waiting } \\
\text { after } \\
\text { Stopping }\end{array}$ & $\begin{array}{c}\text { Pouring } \\
\text { Concrete }\end{array}$ & Leaving & $\begin{array}{c}\text { Pumping } \\
\text { Concrete }\end{array}$ & Cycle \\
\hline $\begin{array}{c}\text { Average of the measured } \\
\text { equipment operation time } \\
\text { (standard deviation) }\end{array}$ & 36.3 & 190.5 & 343.8 & 9.3 & 299.6 & 879.4 \\
\hline $\begin{array}{c}\text { Planned equipment } \\
\text { operation time }\end{array}$ & 36.3 & 190.5 & 343.8 & 9.3 & 246.9 & 826.8 \\
\hline
\end{tabular}

\subsection{Estimating $\mathrm{CO}_{2}$ Emissions}

In this study, $\mathrm{CO}_{2}$ emissions from the oil consumption of construction equipment were estimated. The oil consumption was calculated using the measured working time at the construction site, the fuel efficiency of the construction equipment, and the engine load factor of construction equipment (Equation (2)):

$$
F=T \times F E \times L F
$$

where:

F: Oil Consumption by Work;

$T$ : Working time;

FE: Fuel efficiency of construction equipment;

$L F$ : Engine load factor of construction equipment.

The fuel consumption of the construction equipment is based on the equipment specification information (Table 3). The engine load factors are: Low (20-30\% output, short distance travel); medium (30-40\% output); waiting after stopping (when output is idling at $10 \%)$; and acceleration (100\% output 
and continuous acceleration) [24]. When output is $40-50 \%$, it indicates that the slope has suddenly changed, or there was a long distance of high driving resistance.

Table 3. Engine load factor by detailed operation.

\begin{tabular}{cccccc}
\hline & $\begin{array}{c}\text { Stopping after } \\
\text { Entering }\end{array}$ & $\begin{array}{c}\text { Waiting after } \\
\text { Stopping }\end{array}$ & $\begin{array}{c}\text { Pouring } \\
\text { Concrete }\end{array}$ & Leaving & $\begin{array}{c}\text { Pumping } \\
\text { Concrete }\end{array}$ \\
\hline $\begin{array}{c}\text { Engine load } \\
\text { factor }\end{array}$ & Low $(25 \%)$ & Waiting $(10 \%)$ & $\begin{array}{c}\text { Acceleration } \\
(100 \%)\end{array}$ & Low $(25 \%)$ & $\begin{array}{c}\text { Acceleration } \\
(100 \%)\end{array}$ \\
\hline
\end{tabular}

Using the estimated amount of oil consumption, $\mathrm{CO}_{2}$ emissions for detailed tasks were calculated using Equation (3):

$$
\mathrm{CO}_{2}=F \times T E \times C F \times \frac{44}{12}
$$

where:

TE: Petroleum conversion coefficient; and

CF: Carbon emission coefficient.

In this formula, the type of oil consumed is converted to equivalent oil consumed using an oil conversion factor, since the amount of $\mathrm{CO}_{2}$ consumed differs depending on the type of oil. The converted value is multiplied by the $\mathrm{CO}_{2}$ emission factor to estimate the $\mathrm{CO}_{2}$ emission. The carbon molecular weight ratio to the carbon atom is multiplied by the constant $44 / 12$ to calculate the final $\mathrm{CO}_{2}$ emitted. In this study, the diesel oil conversion factor is 0.000845 toe/ton, and the emission factor is 0.837 ton-C/toe (where toe is ton of oil equivalent).

\subsection{Comparative Analysis of Emissions}

The average $\mathrm{CO}_{2}$ emissions calculated based on the measured operating time and the planned operating time of the equipment were compared. Concrete mixer trucks do not have planned emissions, so they cannot be compared with actual $\mathrm{CO}_{2}$ emissions. A descriptive analysis of the $\mathrm{CO}_{2}$ emissions for the activities and the whole cycle was conducted to examine the variability of $\mathrm{CO}_{2}$ emissions data (Table 4).

Table 4. Descriptive statistics of $\mathrm{CO}_{2}$ emissions for measured operation time $\left(\mathrm{gCO}_{2}\right)$.

\begin{tabular}{|c|c|c|c|c|c|c|c|}
\hline \multicolumn{2}{|c|}{ Activity } & \multirow{2}{*}{\begin{tabular}{|c|}
$\begin{array}{c}\text { Stopping } \\
\text { after } \\
\text { Entering }\end{array}$ \\
85.1 \\
\end{tabular}} & \multirow{2}{*}{$\begin{array}{c}\begin{array}{c}\text { Waiting } \\
\text { after } \\
\text { Stopping }\end{array} \\
178.4 \\
\end{array}$} & \multirow{2}{*}{$\begin{array}{c}\begin{array}{c}\text { Pouring } \\
\text { Concrete }\end{array} \\
3219.7\end{array}$} & \multirow{2}{*}{$\begin{array}{c}\text { Leaving } \\
21.7\end{array}$} & \multirow{2}{*}{$\begin{array}{c}\text { Pumping } \\
\text { Concrete }\end{array}$} & \multirow{2}{*}{\begin{tabular}{|l|} 
Cycle \\
7324.4
\end{tabular}} \\
\hline \multirow{8}{*}{$\begin{array}{l}\text { Emissions for } \\
\text { measured } \\
\text { equipment } \\
\text { operation time }\end{array}$} & Average & & & & & & \\
\hline & Median & 63.2 & 112.4 & 3118.4 & 18.7 & 3664.9 & 7220.7 \\
\hline & $\begin{array}{l}\text { Standard } \\
\text { Deviation }\end{array}$ & 64.0 & 227.8 & 894.2 & 8.1 & 1061.4 & 1877.2 \\
\hline & $\begin{array}{l}\text { Coefficient } \\
\text { of variation }\end{array}$ & 0.8 & 1.3 & 0.3 & 0.4 & 0.3 & 0.3 \\
\hline & Kurtosis & 12.4 & 5.7 & 1.6 & 1.8 & -0.2 & 0.4 \\
\hline & Skewness & 3.3 & 2.5 & 1.0 & 1.4 & 0.4 & 0.6 \\
\hline & Min. Value & 44.5 & 9.4 & 1947.9 & 14.0 & 1879.6 & 3984.3 \\
\hline & Max. Value & 334.8 & 889.6 & 5637.5 & 44.5 & 5903.4 & $11,333.1$ \\
\hline \multicolumn{2}{|c|}{$\begin{array}{l}\text { Emissions for planned } \\
\text { equipment operation time }\end{array}$} & 85.1 & 178.4 & 3219.7 & 21.7 & 3442.6 & 6947.5 \\
\hline
\end{tabular}

The standard deviation, similar to the mean value, appeared to have a large value in the order of pumping concrete, pouring concrete, waiting after stopping, stopping after entering, and leaving. However, the coefficient of variation had the largest value of 1.3 for waiting after stopping, followed by stopping after entering with 0.8 , leaving with 0.4 , and pouring and pumping with 0.3 . Therefore, 
the variation was relatively small in pouring concrete, pumping concrete, and leaving, while it was relatively large for waiting after stopping and stopping after entering. On the other hand, the coefficient of variation for the whole cycle was similar to that of pouring concrete and pumping concrete. Similarly, this is the reason why the emissions of both activities have a high emission rate.

Overall, the amount of $\mathrm{CO}_{2}$ emissions during pouring works is influenced by the high emission ratios of pouring and pumping. Thus, the distribution of emissions and the total emissions from these two activities represent a relatively regular form of distribution. However, since the coefficient of variation exceeds 0.3 for both the detailed and the complete work, the analyzed deviation is relatively large. Moreover, several activities showed a relatively high coefficient of variation and a biased distribution in the emission data even though the emission rate was low. Thus, the estimation of $\mathrm{CO}_{2}$ emissions using a single value may cause a significant error due to an insufficient reflection of the variability. In order to increase the reliability of $\mathrm{CO}_{2}$ emission estimation, it is necessary to consider the variability of $\mathrm{CO}_{2}$ emissions for each activity.

\section{Predicting $\mathrm{CO}_{2}$ Emissions Using a Monte Carlo Simulation}

\subsection{Monte Carlo Simulation}

In this study, Monte Carlo simulation was adopted for probabilistic estimation of $\mathrm{CO}_{2}$ emissions. Monte Carlo simulation was used because it is one of the essential techniques used for probabilistic analysis and it generates a stochastic model for uncertain variables and presents statistical results from the simulated experiment [25]. These statistical results enable effective decision-making under uncertain conditions.

In this study, Crystal Ball software was used to effectively perform Monte Carlo simulations. This software supports probabilistic model analysis and simulation testing of the data required for Monte Carlo simulations. For the application of Monte Carlo simulations in this study, $\mathrm{CO}_{2}$ emissions of one work cycle were set as the result value. In addition, the variables that affect the resultant value were set at $\mathrm{CO}_{2}$ emissions for each activity. Afterward, the Kolmogorov-Smirnov (K-S) test was performed on the activity data to derive the probability distribution model for $\mathrm{CO}_{2}$ emissions from the activities. A correlation analysis was performed between the $\mathrm{CO}_{2}$ emission data for each activity. The simulation was performed by generating random numbers using the correlation analysis results. As a result, the probability model of the resultant value was derived, and the $\mathrm{CO}_{2}$ emissions were analyzed for each activity.

\subsection{The Kolmogorov-Smirnov (K-S) Test}

In this study, the K-S test was used to focus on a typical situation where the number of observations is higher than in certain situations where the equipment takes a long time to run. Comparing the $\mathrm{K}-\mathrm{S}$ test with the Anderson-Darling test, the $\mathrm{K}-\mathrm{S}$ test has the advantage that it is more sensitive in the middle distribution than in the tail [26]. In the K-S test, 14 types of probability distributions are available in the Crystal Ball software. The K-S test was used to test the goodness-of-fit of the emissions data from the measured operation time.

Since the test statistic of the critical value has a significance level of 0.05 and an $N$ value of 21 , it is confirmed to be 0.287 for the K-S test for goodness of fit [27]. The test results indicated that the null hypothesis of the K-S test method adopted in Table 5 for all the sub-tasks is lower than the critical value of 0.287 . Therefore, the probability model of each variable derived from this section sufficiently reflects the distribution of actual data. Analysis showed that the distributions for stopping after entering, waiting after stopping, and leaving activities followed a log normal distribution, whereas pouring concrete followed a logistic distribution, and pumping concrete followed an extremum value distribution (Figure 1). 
Table 5. Kolmogorov-Smirnov (K-S) test of $\mathrm{CO}_{2}$ emissions by activities.

\begin{tabular}{cccccc}
\hline & $\begin{array}{c}\text { Stopping after } \\
\text { Entering }\end{array}$ & $\begin{array}{c}\text { Waiting after } \\
\text { Stopping }\end{array}$ & $\begin{array}{c}\text { Pouring } \\
\text { Concrete }\end{array}$ & Leaving & $\begin{array}{c}\text { Pumping } \\
\text { Concrete }\end{array}$ \\
\hline Fit distribution & Log normal & Log normal & Logistics & Log normal & Extremum value \\
$\mathrm{D}$ & 0.108 & 0.108 & 0.137 & 0.158 & 0.076 \\
\hline
\end{tabular}

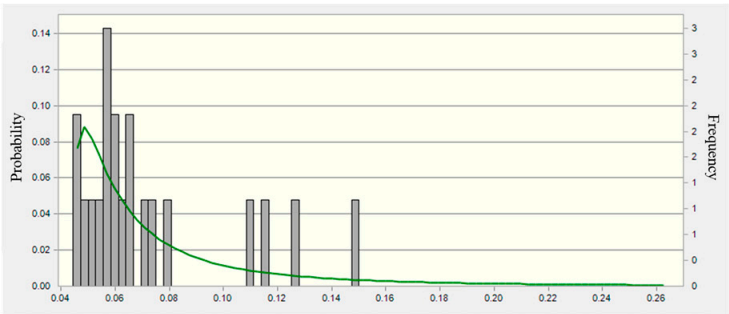

[Stopping after entering]

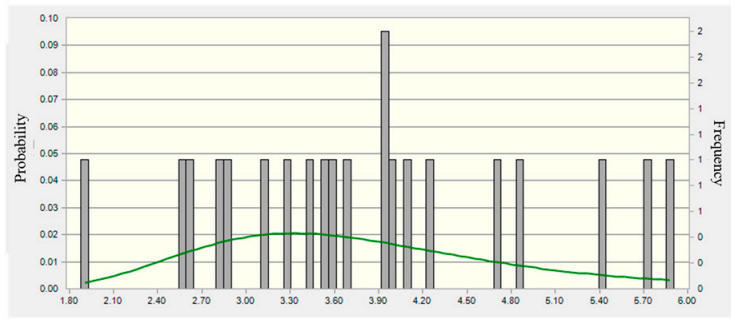

[Pouring concrete]

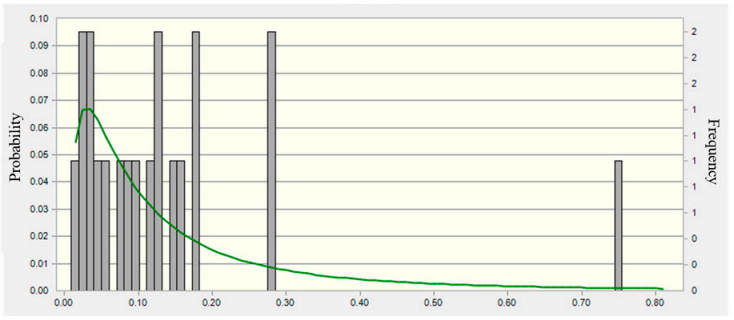

[Waiting after stopping]

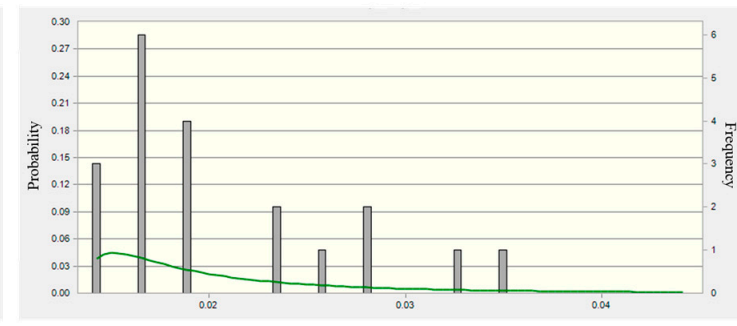

[Leaving]

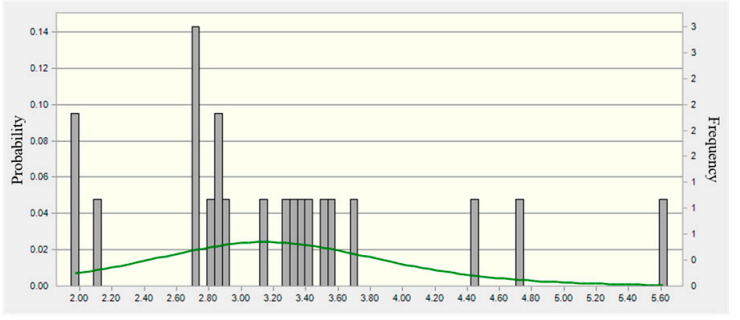

[Pumping concrete]

Figure 1. The plots of distribution by activities.

\subsection{Correlation Analysis}

In this section, correlation analysis is performed to derive the correlation coefficients for the emission amount of each activity and to reflect them in the simulation. The correlation analysis indicated the magnitude of the correlation among the activities through a correlation coefficient. The correlation coefficient range is from -1 to +1 , and the signs of the coefficients indicated whether the relationship of the two variables is proportional or inversely proportional. The absolute value of the coefficient indicates the strength of the relationship. Thus, any value close to +1 or -1 indicates a strong correlation.

This study investigated the correlation between each variable, determined through the Spearman correlation coefficient. The Spearman correlation coefficient is a non-parametric measure of the degree of qualitative correlation of the increase or decrease when the distribution of two successive variables fits a normal distribution or provides rank-scale data. Therefore, the application of Spearman's correlation coefficient can be suitably considered a detailed work-specific fit distribution model that was verified in the previous section.

As a result of the correlation analysis with a significance level of 0.05 , it was confirmed that the correlation between stopping after entering and pouring concrete, stopping after entering and leaving, pumping concrete and waiting after stopping, pumping concrete and pouring concrete was significant 
(Table 6). The highest correlation was found between pumping concrete and pouring concrete with a correlation coefficient of 0.806 because the concrete pump car can pump concrete while concrete pouring work is underway. The correlations between pouring concrete and stopping after entering (0.524), and between stopping after entering and leaving (0.469) appeared to be strongly positive. The reason for the two positive correlations is that these activities are particularly affected by the proficiency of handling the equipment at a busy construction site and of the concrete mixer truck driver. The correlation between waiting after stopping and pumping was -0.469 , indicating a strong negative correlation. This is because the waiting time is longer as the concrete pumping work is delayed.

Table 6. Results of correlation analysis between activities.

\begin{tabular}{cccccc}
\hline Activity & $\begin{array}{c}\text { Stopping after } \\
\text { Entering }\end{array}$ & $\begin{array}{c}\text { Waiting after } \\
\text { Stopping }\end{array}$ & $\begin{array}{c}\text { Pouring } \\
\text { Concrete }\end{array}$ & Leaving & $\begin{array}{c}\text { Pumping } \\
\text { Concrete }\end{array}$ \\
\hline $\begin{array}{c}\text { Stopping after } \\
\text { entering }\end{array}$ & 1 & & & & \\
Waiting after & -0.040 & 1 & & & \\
$\quad$ stopping & $0.339^{*}$ & -0.079 & 1 & 1 & 1 \\
Pouring concrete & 0.284 & $0.617^{* *}$ & 0.140 & 0.110 & 1 \\
Leaving & $0.387^{*}$ & -0.298 & $0.854^{* *}$ & & \\
Pumping concrete &
\end{tabular}

* Significant at 0.05 level of significance. ${ }^{* *}$ Significant at 0.01 level of significance.

\subsection{Simulation Test Results and Analysis}

In this study, we executed the simulation test 10,000 times at a $95 \%$ confidence interval. To calculate the confidence interval, instead of a mathematical formula, we used an analytical bootstrapping method [28]. The simulation tests were performed by taking into account the probability distribution model obtained from the fit and the calculated correlation coefficient. The random values were generated considering the correlation to the probability distribution of a particular activity, and the results were obtained stochastically. The upper and lower limits of emissions were determined by adjusting the confidence interval.

The results of the simulation were similar to the corresponding figures of the measured operating time-based emissions data (Table 7). However, in the case of kurtosis and skewness, a significant difference was noticed in the corresponding figures in the $\mathrm{CO}_{2}$ emission data based on the measured operating hours. The significant differences are because the tendency in the form of $\mathrm{CO}_{2}$ emission distribution was strongly reflected by the performance of the repeated imitating experiment. The degree of deviation was significantly different from the corresponding values of the emission data based on the measured operating time of equipment.

As a result of the simulation, the $\mathrm{CO}_{2}$ emission probability model of the pouring work follows the log normal distribution (Figure 2). At a 95\% confidence interval, the lower limit of emissions is $4171.7 \mathrm{~g} \mathrm{CO}_{2}$, the upper limit is $11,705.4 \mathrm{~g} \mathrm{CO}_{2}$, and the average is $7329.7 \mathrm{~g} \mathrm{CO}_{2}$.

This study analyzed $\mathrm{CO}_{2}$ emissions estimated by current deterministic methods as a single value using the derived probability distribution model. The results of the analysis of the estimated current $\mathrm{CO}_{2}$ emissions were outside the $95 \%$ confidence interval of the probability distribution model or about $20 \%$ different from the mean value (Figure 3). In the probability distribution model, the probability of $\mathrm{CO}_{2}$ emissions being less than those estimated by the CECET was found to be about $0.6 \%$ (i). Therefore, it is estimated that there is a risk of underestimating emissions because the level of emissions was estimated at a level that exceeds the $95 \%$ confidence interval of the simulation results. In addition, the probability of actual measured $\mathrm{CO}_{2}$ emissions being less than the estimated $\mathrm{CO}_{2}$ emissions using a bill of quantity was $73.2 \%$ in the probability distribution model (iii). The value of the result is within the $95 \%$ confidence interval of the probability distribution model. However, it is considered that the $\mathrm{CO}_{2}$ emission calculation method using a bill of quantity may over-calculate compared to actual $\mathrm{CO}_{2}$ 
emissions because the corresponding probability differs by more than $20 \%$ from the average value of the probability distribution model.

Table 7. Simulated test results (units are $\mathrm{gCO}_{2}$ ).

\begin{tabular}{|c|c|c|c|c|c|c|c|}
\hline \multicolumn{2}{|c|}{ Activity } & $\begin{array}{l}\text { Stopping } \\
\text { after } \\
\text { Entering }\end{array}$ & $\begin{array}{l}\text { Waiting } \\
\text { after } \\
\text { Stopping }\end{array}$ & $\begin{array}{l}\text { Pouring } \\
\text { Concrete }\end{array}$ & Leaving & $\begin{array}{l}\text { Pumping } \\
\text { Concrete }\end{array}$ & Cycle \\
\hline \multirow{8}{*}{$\begin{array}{l}\text { Simulated test } \\
\text { result } \\
\text { emissions }\end{array}$} & Average & 86.1 & 186.4 & 3164.6 & 22.4 & 3871.1 & 7329.7 \\
\hline & Median & 64.4 & 98.4 & 3168.6 & 18.7 & 3.668.7 & 7165.1 \\
\hline & $\begin{array}{l}\text { Standard } \\
\text { Deviation }\end{array}$ & 74.8 & 316.6 & 875.1 & 11.8 & 1186.3 & 186.9 \\
\hline & $\begin{array}{l}\text { Coefficient } \\
\text { of variation }\end{array}$ & 0.9 & 1.7 & 0.3 & 0.5 & 0.3 & 0.3 \\
\hline & Kurtosis & 107.7 & 226.5 & 4.2 & 47.4 & 6.0 & 3.5 \\
\hline & Skewness & 7.58 & 10.5 & 0.0 & 4.8 & 1.2 & 0.5 \\
\hline & Lower* & 45.0 & 11.0 & 1428.1 & 13.9 & 2152.3 & 4171.7 \\
\hline & Upper * & 262.6 & 890.2 & 4941.6 & 53.5 & 6694.1 & $11,705.4$ \\
\hline \multicolumn{2}{|c|}{$\begin{array}{l}\text { Emissions based on planned } \\
\text { equipment operation time }\end{array}$} & 85.8 & 175.1 & 2718.2 & 21.6 & 3448.2 & 6831.4 \\
\hline
\end{tabular}

*95\% confidence interval.

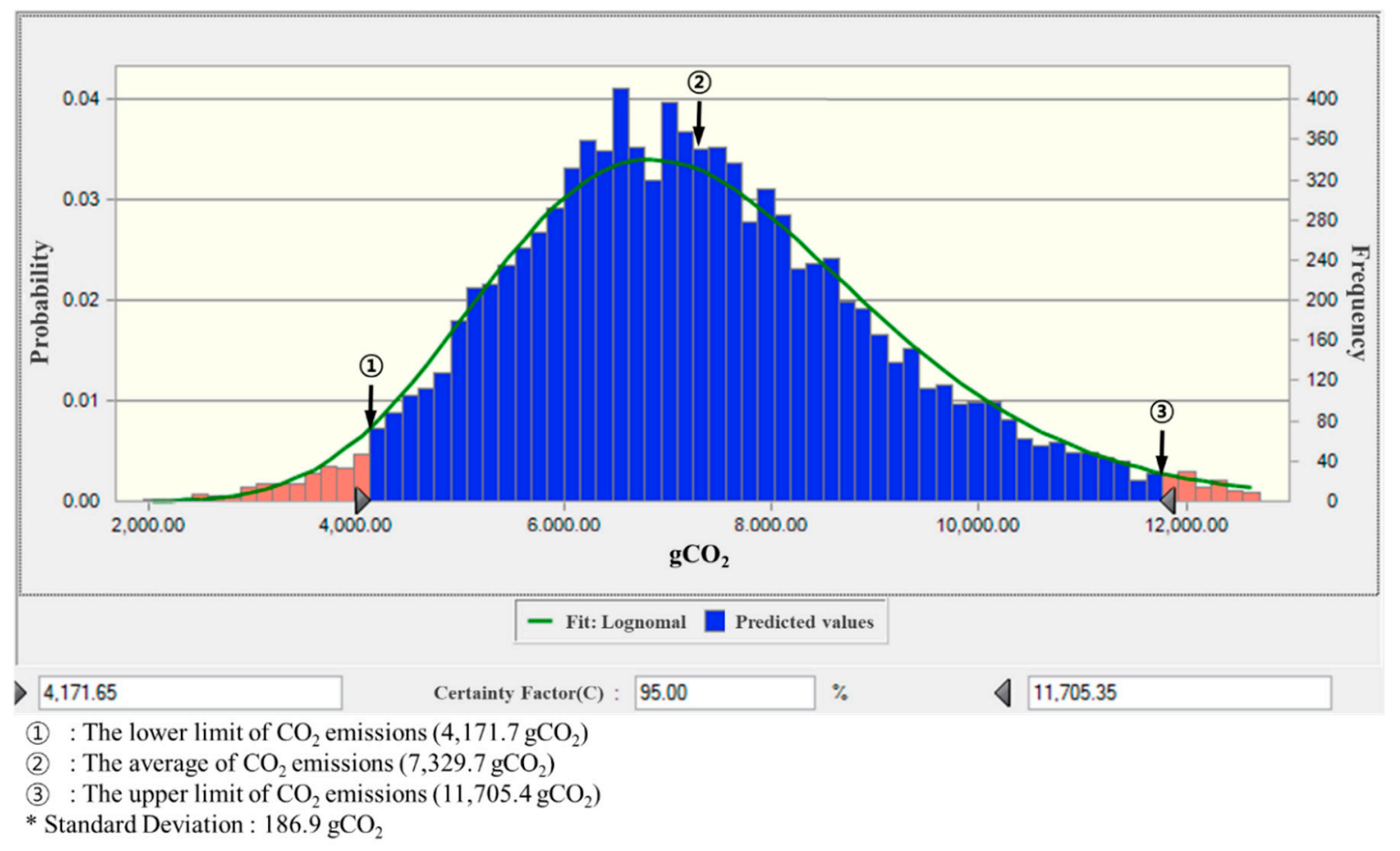

Figure 2. The probability model of $\mathrm{CO}_{2}$ emissions in concrete pouring work according to simulation results.

Consequently, using actual measured data, probability-based estimation and analysis of $\mathrm{CO}_{2}$ emissions will be more realistic and accurate for the construction planning phase as well as for the construction phase. The current methods of estimating $\mathrm{CO}_{2}$ emissions are analyzed to have differences with actual $\mathrm{CO}_{2}$ emissions, so further verification or improvement of the current methods of estimation is needed. It is also possible to assess quantitatively whether $\mathrm{CO}_{2}$ emissions are likely to be over- or under-estimated by reviewing the probability distribution model for specific construction work. 
(1)

(2)

(3)

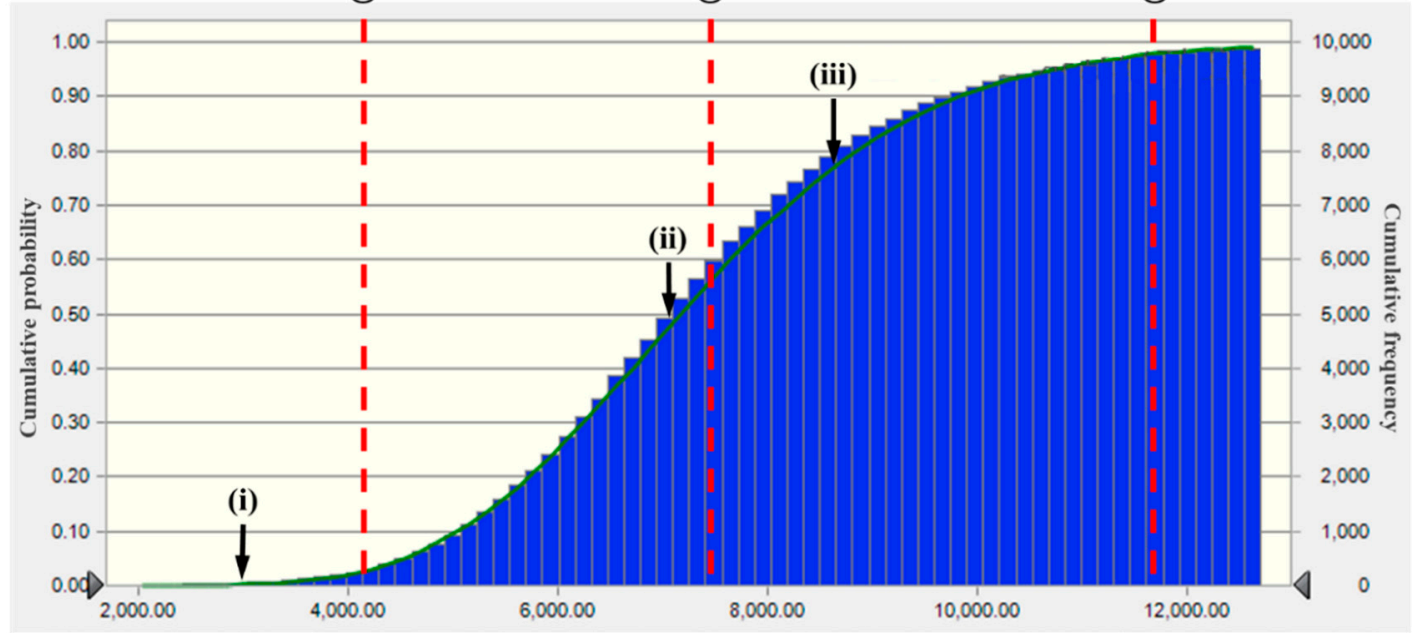

(1) : The lower limit of $\mathrm{CO}_{2}$ emissions $\left(4,171.7 \mathrm{gCO}_{2}\right)$

(2) : The average of $\mathrm{CO}_{2}$ emissions $\left(7,329.7 \mathrm{gCO}_{2}\right)$

(3) : The upper limit of $\mathrm{CO}_{2}$ emissions $\left(11,705.4 \mathrm{gCO}_{2}\right)$

(i) : $\mathrm{CO}_{2}$ emissions as calculated by Construction Equipment Expense Calculation Table $\left(3,147.5 \mathrm{gCO}_{2}, 0.6 \%\right)$

(ii) : Amount of emissions equal to $50 \%$ of the probability model $\left(7,134.8 \mathrm{gCO}_{2}, 50.0 \%\right)$

(iii) : $\mathrm{CO}_{2}$ emissions as calculated by the bills of quantity $\left(8,262.3 \mathrm{gCO}_{2}, 73.2 \%\right)$

Figure 3. Analysis of $\mathrm{CO}_{2}$ emissions using the probability model.

\section{Conclusions}

This study gathered data on the operation time of construction equipment at the activity level and performed a probabilistic analysis using Monte Carlo simulations to determine the variability of $\mathrm{CO}_{2}$ emissions during the construction phase.

This study used actual activity data to account for variability in the construction phase, and probabilistic estimation showed that the current deterministic methods are insufficient to predict $\mathrm{CO}_{2}$ emissions at the planning and design phases. It is suggested that actual activity data collection and probabilistic analyses for activity data are necessary to present highly reliable $\mathrm{CO}_{2}$ emission estimation. Risk information from the probabilistic emission calculation methods presented in this study may support decision makers to establish more realistic reduction goals in developing greenhouses gas and energy consumption reduction strategies.

This study dealt with the $\mathrm{CO}_{2}$ emissions of the construction process stage within the life-cycle assessment (LCA) system boundaries. The $\mathrm{CO}_{2}$ emissions from the construction process stage are known to account for less than those of the operational use stage in the building life cycle. Thus, the variability of the construction phase covered in this study may not have a significant impact on the $\mathrm{CO}_{2}$ emissions of the whole life cycle. Nevertheless, the importance of embedded carbon, including $\mathrm{CO}_{2}$ emissions from the current construction process stage, has been emphasized. In particular, according to the zero-energy building concept, which has recently become a reality, $\mathrm{CO}_{2}$ emissions from the operational use stage will be close to zero in the future, and the calculation of carbon emissions from the construction process stage will be important.

However, this study was limited to the activity data gathered from concrete work only and considered variability at the activity level only in terms of construction equipment operation time. In future studies, we will gather further actual activity data during the construction process. In addition, we will derive the additional factors affecting $\mathrm{CO}_{2}$ emissions during the construction phase and calculate the derived weights of the factors. The $\mathrm{CO}_{2}$ emissions from the construction process will also be implemented as a probabilistic model with calculated weights. 
Author Contributions: Data curation, C.N.; Formal analysis, D.L. and C.N.; Investigation, D.L. and C.N.; Methodology, D.L., G.K. and C.N.; Project administration, H.C and K.-I.K.; Supervision, K.-I.K.; Writing-original draft, D.L.; Writing-review \& editing, D.L., G.K. and H.C.; funding acquisition, K.-I.K.

Funding: This research was funded by National Research Foundation of Korea grant number 2016R1A2B3015348 and Architecture \& Urban Development Research Program funded by the Ministry of Land, Infrastructure and Transport of the Korean Government grant number 19AUDP-B121595-04.

Acknowledgments: This research was supported by National Research Foundation of Korea grant number 2016R1A2B3015348 and Architecture \& Urban Development Research Program funded by the Ministry of Land, Infrastructure and Transport of the Korean Government grant number 19AUDP-B121595-04.

Conflicts of Interest: The authors declare no conflict of interest.

\section{References}

1. United Nations Environment Programme. Sustainable Buildings \& Contruction Initiative: Information Note; United Nations Environment Programme: Nairobi, Kenya, 2006.

2. Ibn-Mohammed, T.; Greenough, R.; Taylor, S.; Ozawa-Meida, L.; Acquaye, A. Operational vs. embodied emissions in buildings-A review of current trends. Energy Build. 2013, 66, 232-245. [CrossRef]

3. Zuo, J.; Pullen, S.; Rameezdeen, R. Green building evaluation from a life-cycle perspective in Australia: A critical review. Renew. Sustain. Energy Rev. 2017, 70, 358-368. [CrossRef]

4. Geng, S.; Wang, Y.; Zuo, J.; Zhou, Z.; Du, H.; Mao, G. Building life cycle assessment research: A review by bibliometric analysis. Renew. Sustain. Energy Rev. 2017, 76, 176-184. [CrossRef]

5. Daewoo Engineering \& Construction Co., Ltd. 2014 Daewoo EEC Sustainability Report; Daewoo Engineering \& Construction Co., Ltd.: Seoul, Korea, 2014.

6. Gonzalez, V.; Echaveguren, T. Exploring the environmental modeling of road construction operations using discrete-event simulation. Autom. Constr. 2012, 24, 100-110. [CrossRef]

7. Intergovernmental Panel on Climate Change. 2006 IPCC Guidelines for National Greenhouse Gas Inventories Volume 1 General Guidance and Reporting. Available online: https://www.ipcc-nggip.iges.or.jp/public/ 2006gl/ (accessed on 22 July 2019).

8. Monahan, J.; Powell, J. An embodied carbon and energy analysis of modern methods of construction in housing: A case study using a lifecycle assessment framework. Energy Build. 2011, 43, 179-188. [CrossRef]

9. Roh, S.; Tae, S. An Analysis of the Life Cycle Embodied Carbon Emissions of Apartment Buildings Using Probabilistic Analysis Method. J. Archit. Inst. Korea Struct. Constr. 2017, 33, 65-72. [CrossRef]

10. Choi, D.; Jeon, H.; Shin, D.; Cho, K. A Study of Fuel Consumption and Carbon Dioxide Emission at the Construction Operation Phase of Apartment Buildings through Analysis on Construction Statements. J. Archit. Inst. Korea Struct. Constr. 2015, 31, 277-282.

11. Hong, J.; Shen, G.Q.; Feng, Y.; Lau, W.S.T.; Mao, C. Greenhouse gas emissions during the construction phase of a building: A case study in China. J. Clean. Prod. 2015, 103, 249-259. [CrossRef]

12. Jun, S.E.; Lim, T.K.; Lee, D.E. A System for Estimating $\mathrm{CO}_{2}$ Emission using the Construction Project Schedule Information. J. Archit. Inst. Korea Struct. Constr. 2011, 27, 169-176.

13. Ahn, C.B.; Lee, S.H. Importance of Operational Efficiency to Achieve Energy Efficiency and Exhaust Emission Reduction of Construction Operations. J. Constr. Eng. Manag. 2012, 139, 404-413. [CrossRef]

14. Cass, D.; Mukherjee, A. Calculation of Greenhouse Gas Emissions for Highway Construction Operations by Using a Hybrid Life-Cycle Assessment Approach: Case Study for Pavement Operations. J. Constr. Eng. Manag. 2011, 137, 1015-1025. [CrossRef]

15. Zhang, H. Simulation-based estimation of fuel consumption and emissions of asphalt paving operations. J. Comput. Civ. Eng. 2014, 29, 04014039. [CrossRef]

16. Kim, B. Correlation Analysis on the Duration and CO Emission Following the Earth-Work Equipment Combination. J. Korean Soc. Civ. Eng. 2011, 31, 603-611.

17. Kim, B.; Lee, H.; Park, H.; Kim, H. Greenhouse gas emissions from onsite equipment usage in road construction. J. Constr. Eng. Manag. 2011, 138, 982-990. [CrossRef]

18. Yi, C.Y.; Gwak, H.S.; Lee, D.E. Stochastic carbon emission estimation method for construction operation. J. Civ. Eng. Manag. 2017, 23, 137-149. [CrossRef]

19. Yi, C.Y.; Gwak, H.S.; Lee, D.E. Methodology for Estimating Stochastic CO Emission for Construction Operation. J. Archit. Inst. Korea Struct. Constr. 2014, 30, 45-54. [CrossRef] 
20. Nam, C.; Lee, D.; Kang, G.; Cho, H.; Kang, K.I. Activity based prediction of on-site $\mathrm{CO}_{2}$ emissions containing uncertainty. In Proceedings of the 34th International Symposium on Automation and Robotics in Construction, Taipei, Taiwan, 28 June-1 July 2017; pp. 1085-1092.

21. Kang, G.; Kim, T.; Kim, Y.W.; Cho, H.; Kang, K.I. Statistical analysis of embodied carbon emission for building construction. Energy Build. 2015, 105, 326-333. [CrossRef]

22. Acquaye, A.; Duffy, A.; Basu, B. Stochastic hybrid embodied $\mathrm{CO}_{2}$-eq analysis: An application to the Irish apartment building sector. Energy Build. 2011, 43, 1295-1303. [CrossRef]

23. Intergovernmental Panel on Climate Change. 2006 IPCC Guidelines for National Greenhouse Gas Inventories Volume 2 Energy. Available online: https://www.ipcc-nggip.iges.or.jp/public/2006gl/ (accessed on 22 July 2019).

24. Korea Institue of Construction Technology. 2018 Standard of Construction Estimate; Korea Institue of Construction Technology: Goyang, Korea, 2018.

25. Touran, A.; Wiser, E.P. Monte Carlo technique with correlated random variables. J. Constr. Eng. Manag. 1992, 118, 258-272. [CrossRef]

26. Huynh, V.; Nakamori, Y.; Lawry, J.; Inuiguchi, M. Integrated Uncertainty Management and Applications; Springer Science \& Business Media: Berlin, Germany, 2010.

27. Sachs, L. Angewandte Statistik: Anwendung Statistischer Methoden; Springer: Berlin/Heidelberg, Germany, 2013.

28. Oracle EPM Information Development Team. Oracle Crystal Ball Reference and Examples Guide, Release 11.1.2.4.850. 2017. Available online: https://docs.oracle.com/cd/E57185_01/CBREG/toc.htm (accessed on 22 July 2019).

(C) 2019 by the authors. Licensee MDPI, Basel, Switzerland. This article is an open access article distributed under the terms and conditions of the Creative Commons Attribution (CC BY) license (http://creativecommons.org/licenses/by/4.0/). 